\title{
Strange Physics: Time -Travel From The Backyard Of Your Own Garden Together With Chronology Protection \& Closed Time-Like Curves Pre-Existing In the Domain Wall Boundary By Means of Generating A 5-Dimensional Space Through Rotating Frames Of Reference In A Unique Way As To Emphasize Fictions
}

Deep Bhattacharjee ${ }^{1}$ and Deep Bhattacharjee ${ }^{2}$

${ }^{1}$ Affiliation not available

${ }^{2}$ Project Director of AATWRI -R\&D Directorate of Electro-Gravitation Simulation \& Propulsion Laboratory

August 25, 2021

\begin{abstract}
Comment: Time itself being the temporal dimensions can be manipulated by means of clever physics so as to make a time travelling domain in the backyard of your own garden. The principles of this are introduced along with physics, so as to capture the beauty of time travelling on a grander scale by some arbitrarily modified civilizations in the faraway futures. This starts with the basic notions on the perspectives of time with regards to its implications in the physics of the time travel.
\end{abstract}

\section{Hosted file}

Strange Physics-pdf.pdf available at https://authorea.com/users/379677/articles/535118strange-physics-time-travel-from-the-backyard-of-your-own-garden-together-withchronology-protection-closed-time-like-curves-pre-existing-in-the-domain-wall-boundaryby-means-of-generating-a-5-dimensional-space-through-rotating-frames-of-reference-in-aunique-way-as-to-emphasize-fictions 